\title{
The Evaluation for Educational Investments
}

\author{
Tongru $\mathrm{Li}^{1, \text { a }}$ \\ ${ }^{1}$ School of North China Electric Power University, Baoding 071000, China \\ a15733253368@163.com
}

Keywords: Evaluation system; grey correlation analysis;

\begin{abstract}
This paper establishes a evaluation system for educational investments and quotes the method of Grey Correlation Analysis to evaluate schools of the candidate list. The evaluation system for investments is consisted of six indexes: investment intensity, the reasonability of investments region, the reasonability of investments structure, the sustainability of investments, return on investment (ROI), and the potential for effective use of funds. ROI is measured reasonably by economic benefit, the academic level, and the regional advantage. In consideration of gray features of educational investments and multi-levels of index system, the Grey Correlation Analysis is adopted to evaluate the candidate schools. The results of evaluation show the school with the outstanding educational quality, huge teaching scales and excellent locations will have more vast investment potential and top ranking at the candidate list.
\end{abstract}

\section{Introduction}

The investment in education is the basis for the development of intelligence, the development of education and it is an important factor for the economic development and social development. In the long run, the investment in education has the biggest benefit for all kinds of investments. There is no doubt that it is important to pay attention to the investment in education[1].

To help improve educational performance of undergraduates attending colleges and universities in the United States, the Goodgrant Foundation intends to invest in education and donate a total of US100 million to schools per year, for five years. It wants to evaluate schools of the candidate list.

\section{The establishment of Evaluation System}

\subsection{Investment intensity $\left(V_{1}\right)$}

(1). The support of federal government and the rate of loan

Due to the exorbitant cost of infrastructure project of schools, at present the appropriation of federal government is still the main educational funds source of American colleges. Besides, Pell Grants have been given to some colleges by Ministry of Federal Education.

Let $V_{11} 、 V_{12}$ denote PCTPELL and PCTFLOAN. And $V_{11}=1-$ PCTPELL, $V_{12}=$ PCTFLOAN. (Remark: italics represent abbreviations of the corresponding indicators)

(2) The number of students

The number of students developed by investments projects has a direct impact on the investment intensity. The UGDS (Enrollment of undergraduate degree-seeking students) is proportional to the investment intensity, which means that investment intensity depends on the number of students.

Let $V_{13}=4 \times U G D S$.

(3) Control of institution

There are three types of schools: public, private nonprofit, private for-profit. Considering the Goodgrant Foundation is a charitable organization, schools private for-profit will be excluded from consideration. Let $V_{14}$ denotes CONTROL (Control of institution).

\subsection{The reasonability of investments region $\left(V_{2}\right)$}

Investments in the dominant region will bring additional benefits. For example, the dominant region is more attractive for outstanding teachers and students, which leads to an excellent region 
aggregation effect. In order to simplify the practical situation, the LOCALE (Locale of institution) is used to measure the reasonability of investment region.

\subsection{The reasonability of investments structure $\left(V_{3}\right)$}

(1) The reasonability of academic training level

The schools which are entirely graduate-degree granting colleges, aiming to develop high-quality students, should be paid more attention. Let $V_{31}$ denotes PREDDEG. $V_{31}=$ PREDDEG

(2) The reasonability of major structure

Compared with schools of a small quantity of majors, more educational investments funds are intended to schools with abundant majors, which will be helpful to comprehensive development of schools.

The number of major of one school is determined as follows:

$$
m j r=\sum_{i=1}^{54} I\left(P C I P_{i}\right)
$$

Where,

$$
I\left(\text { PCIP }_{i}\right)= \begin{cases}0, & \text { if } P C I P_{i}=0 \\ 1, & \text { if } P C I P_{i} \neq 0\end{cases}
$$

Let $V_{32}$ denotes $m j r . V_{32}=m j r$.

\subsection{The sustainability of investments $\left(V_{4}\right)$}

Sustainable development of schools is an essential reference index to measure the value of education investment, great importance should be attached to those schools with have good sustainability. Sustainable development of schools can be measured by quality of education.

The index $V_{41}, V_{42}$ denote the quality of education.

$$
V_{41}=\left\{\begin{array}{l}
C 150 \_4 \_P O O L E D_{-} S U P P, \text { if } C 200_{-} L_{4} 4_{-} P O O L E D_{-} S U P P=\text { null } \\
C 200_{-} 4_{-} \text {POOLED_SUPP, if } C 150_{-} 4_{-} P O O L E D_{-} S U P P=\text { null }
\end{array}\right.
$$

The data of $V_{42}$ comes from SAT_AVG(Average SAT equivalent score of students admitted). $V_{42}=$ SAT_AVG.

\subsection{Return on investment (ROI)}

In this paper, the formula of ROI of school $i$ defined in a manner appropriate for a charitable organization is as follows,

$$
\begin{aligned}
R O I_{i} & =r_{i} \times f_{\text {adm }, i} \times f_{\text {reg }, i} \\
& =\frac{\left(E_{i}-D_{i}\right) N_{i}}{\max _{i}\left\{\left(E_{i}-D_{i}\right) N_{i}\right\}} \times f_{\text {adm }, i} \times f_{\text {reg }, i}
\end{aligned}
$$

Where, $f_{a d m, i}=\frac{m j r_{i}}{\sum_{i} m j r_{i}} s_{i}, f_{\text {reg, } i}=\frac{l_{i}}{\bar{l}}$, symbols and their descriptions of the formula ROI are in Tab1.

Tab.1 Symbols and their descriptions of the formula ROI

\begin{tabular}{cll}
\hline Symbols & Descriptions & Formula \\
\hline$f_{a d m, i}$ & The academic level coefficient of school $i$ & --- \\
$f_{\text {reg, } i}$ & The regional advantage coefficient of school $i$ & --- \\
$N_{i}$ & The number of graduates of school $i$ & --- \\
$l_{i}$ & The locale scale of school $i$ & --- \\
$r_{i}$ & Economic benefit rate created by graduates of school $i$ & $r_{i}=($ earn - debt $) \times n_{\text {gradute }}$ \\
$s_{i}$ & Scientific research level of school $i$ & $s_{i}=$ PREDDEG \\
$E_{i}$ & The median earnings of students of school $i$ & $E_{i}=$ md_earn_wne_p10 $_{-}$ \\
$D_{i}$ & The median debt of students of school $i$ & $D_{i}=12 \times G R A D_{-}$DEBT_MDN10YR \\
\hline
\end{tabular}




\subsection{The potential for effective use of funds $\left(V_{6}\right)$}

Use the education scale、 education quality and academic training level to quantify the potential for effective use of funds.

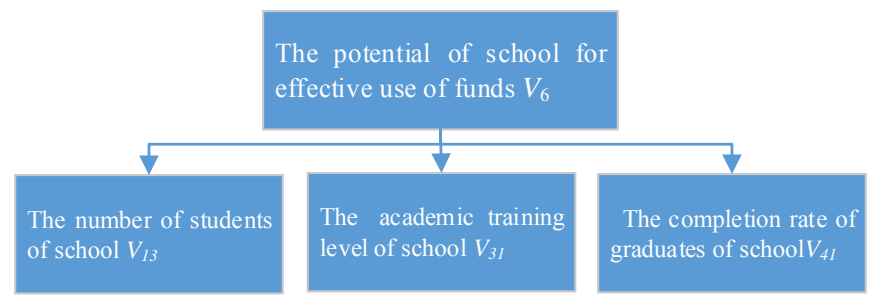

Fig. 1 The Schematic diagram of $\mathrm{V}_{6}$

The formula of the potential for effective use of funds is as follows,

$V_{6, i}=\frac{V_{13, i}}{\bar{V}_{13}} \times \frac{V_{41, i}}{\bar{V}_{41}} \times \frac{V_{31, i}}{\max V_{31}}$

\section{The evaluation method of Grey Correlation Analysis}

\subsection{The calculation for second-class indexes $\rightarrow$ first-class indexes}

The formula of $V_{1}$ is as follows,

$V_{1}=\left(V_{11}+V_{12}\right) V_{13} \times V_{14}$

Where $V_{1}$ is the investment intensity. And $V_{11}, V_{12}, V_{13}$ are $1-P C T P E L L$ (the percentage of undergraduates who receive a Pell Grant), PCTFLOAN(Percent of all federal undergraduate students receiving a federal student loan), the number of students of a school. And $V_{14}$ demonstrates the type of a school (public, private nonprofit, private for-profit).

The formula of $V_{3}$ is as follows,

$$
V_{3}=\left(\frac{V_{31}}{\bar{V}_{31}}+\frac{V_{32}}{\bar{V}_{32}}\right) / 2
$$

Where, $V_{3}$ is the reasonability of investments structure, $V_{31}$ shows the academic training level and $V_{32}$ show the number of major of a school. $\bar{V}_{31}$ is the average value of $V_{31}$ of all candidate schools and $\bar{V}_{32}$ is the average value of $V_{32}$ of all candidate schools

The formula of $V_{4}$ is derived as follows,

$$
V_{4}=\left(V_{41}+\frac{V_{42}}{\bar{V}_{42}}\right) / 2
$$

Where, $V_{4}$ is the sustainability of investments, $V_{41}$ indicates the completion rate of a school and $V_{42}$ is the average SAT equivalent score of students admitted.

\subsection{The calculation for first-class indexes $\rightarrow$ Final evaluation value}

The potential of schools for educational investments (final evaluation value) is calculated by using the method of Grey Correlation Analysis [2,3,4].

Step1. The number of evaluation objects (Candidate schools) is $n$, and the number of indexes is $m$. Let $x_{0}=\{x(k) \mid k=1,2, \ldots, m\}$ demonstrates referenced sequence and $x_{i}=\left\{x_{i}(k) \mid k=1,2, \ldots m\right\}, i=1,2, \ldots n$ demonstrates compared sequence.

In this paper, let $x_{0}(k)=\max _{i}\left\{x_{i}(k)\right\}, k=1, \ldots, 6$, which indicates the index with maximal value is most valuable reference index.

Step2. Calculate the weight of indexes $\mathrm{w}=[\mathrm{w} 1, \ldots, \mathrm{wm}]$. Based on score matrixes for $\mathrm{V}=\{\mathrm{V} 1, \ldots, \mathrm{V} 6\}$ from three teachers and seven students, the Analytic Hierarchy Process(AHP) is quoted to calculate the weight $\mathrm{w}$. Omit algorithm narrative process for AHP. The final result is $\mathrm{w}=[0.14,0.05,0.21,0.12,0.31,0.17]$

Step3. Calculate the grey correlation coefficient:

$$
\eta_{i}(k)=\frac{\operatorname{minmin}_{s}\left|x_{0}(t)-x_{s}(t)\right|+\rho \max _{s} \max _{t}\left|x_{0}(t)-x_{s}(t)\right|}{\left|x_{0}(t)-x_{i}(t)\right|+\rho\left|x_{0}(t)-x_{s}(t)\right|}
$$


Where $\rho \in[0,1]$ is the resolution coefficient. Let $\rho=0.5$.

Step4. Calculate the gray correlation result $[5,6]$. The formula of gray correlation is as follows,

$r_{i}=\sum_{k=1}^{m} w_{i} \eta_{i}(k), i=1,2, \ldots n$

A high value of $r$ represents a strong correlation which indicates an excellent evaluation. The value of $r$ shows the final evaluation value -- the potential of schools for educational investments.

\section{The results of evaluation model -- the candidate list}

Based on the evaluation system and the evaluation method of grey correlation Analysis, the part results for the candidate list is in Tab2

Tab.2 Part of the candidate list

\begin{tabular}{lc}
\hline \multicolumn{1}{c}{ INSTNM } & Gray correlation result $r$ \\
\hline Ohio State University-Main Campus & 0.708552081 \\
Texas A \& M University-College Station & 0.702390747 \\
University of Central Florida & 0.700274986 \\
Pennsylvania State University-Main Campus & 0.691720627 \\
Louisiana State University and Agricultural \& Mechanical College & 0.683516199 \\
Michigan State University & 0.680418417 \\
The University of Texas at Austin & 0.652865304 \\
Liberty University & 0.650928021 \\
\hline
\end{tabular}

As the evaluation system shows, when the school has a large number of students, large city scale, abundant subjects, a high ROI and potency of effective use for funds, it will have great potential for educational investment. The final evaluation result reflects this characteristic.

\section{Conclusions}

Establish the evaluation system for educational investments and quotes the method of Grey Correlation Analysis to evaluate schools of the candidate list. The results indicate the school with the outstanding educational quality, huge teaching scales and excellent locations has the vast investment potential and top ranking at the candidate list.

\section{References}

[1] Mohit Tiwari,Kuwar Mausam,Kamal Sharma,Ravindra Pratap Singh. Investigate the Optimal Combination of Process Parameters for EDM by Using a Grey Relational Analysis[J]. Procedia Materials Science,2014,5:

[2] Tsai M S, Hsu F Y. Application of grey correlation analysis in evolutionary programming for distribution system feeder reconfiguration[J]. Power Systems, IEEE Transactions on, 2010, 25(2): 1126-1133.

[3] Xianglong Luo, Yongzhen Wang,Jun Zhao,Ying Chen,Songping Mo,Yulie Gong. Grey relational analysis of an integrated cascade utilization system of geothermal water[J]. International Journal of Green Energy,2016,131:

[4] ZHANG F, SU W. 2, ZHOU Ji-xial (1Department of Geography, Chongqing Normal University, Chongqing 400047, China; 2Institute of Mountain Resource, Guizhou Academy of Sciences, Guiyang 550001, China); Assessment of urban ecological security based on entropy-weighted gray correlation analysis $[\mathrm{J}][\mathrm{J}]$. Chinese Journal of Ecology, 2008, 7.

[5] Tao R H Y Y Z, Yuangang X X Z. Evaluation on cooperative partners in organization coalition for mega projects based on cloud model and gray correlation analysis $[\mathrm{J}][\mathrm{J}]$. China Civil Engineering Journal, 2011, 8: 021. 
[6] Saaty T L. Decision making with the analytic hierarchy process[J]. International journal of services sciences, 2008, 1(1): 83-98. 